\title{
Interactions between arbuscular mycorrhizal fungi and phosphate-solubilizing fungus (Mortierella sp.) and their effects on Kostelelzkya virginica growth and enzyme activities of rhizosphere and bulk soils at different salinities
}

\author{
Huanshi Zhang • Xianghua Wu • Gang Li • Pei Qin
}

Received: 19 October 2010 /Revised: 11 February 2011 /Accepted: 19 February 2011 /Published online: 9 April 2011

(C) The Author(s) 2011. This article is published with open access at Springerlink.com

\begin{abstract}
This study investigated the interactions between two arbuscular mycorrhizal fungi (AMF) (Glomus aggregatum and Glomus mosseae) and a P-solubilizing fungus (Mortierella sp.), with respect to their effects on growth of Kostelelzkya virginica and urease, invertase, neutral phosphatase, alkaline phosphatase, and catalase activities of rhizosphere and bulk soils at different salinity levels (i.e., $0,100,200$, and $300 \mathrm{mM} \mathrm{NaCl}$ ). Percentage of AMF colonization, Mortierella sp. populations, $\mathrm{pH}$, electrical conductivity, and available $\mathrm{P}$ concentration in soil were also determined. Combined inoculation of AMF and Mortierella sp. increased the percentage of AMF colonization and Mortierella sp. populations under salt stress (i.e., 100, 200, and $300 \mathrm{mM} \mathrm{NaCl}$ ). The dual inoculation of Mortierella sp. with $\operatorname{AMF}$ ( $G$. aggregatum or G. mosseae) had significant effects on shoot and root dry weights and available $\mathrm{P}$ concentrations, $\mathrm{pH}$ values, and electrical conductivities of rhizosphere and bulk soils under salt stress. The inoculation of Mortierella sp. significantly enhanced the positive effects
\end{abstract}

\footnotetext{
H. Zhang $\cdot \mathrm{X}$. Wu $\cdot$ G. Li $\cdot$ P. Qin

Halophyte Research Lab of Nanjing University,

Nanjing 210093, China

$\mathrm{X} . \mathrm{Wu}$

School of Biochemical and Environmental Engineering,

Nanjing Xiaozhuang University,

Nanjing 211171, China

P. Qin $(\square)$

School of Life Science, Nanjing University,

Hankou Road 22,

Nanjing, China

e-mail: qinpei@nju.edu.cn
}

of AMF on some enzyme activities (i.e., neutral phosphatase, alkaline phosphatase, and catalase in bulk soil; neutral phosphatase and urease in rhizosphere soil); on the contrary, it produced negative effects on urease activities in bulk soil and invertase activities in bulk and rhizosphere soils. The results indicated that the most effective co-inoculation was the dual inoculation with Mortierella sp. and G. mosseae, which may help in alleviating the deleterious effects of salt on plants growth and soil enzyme activities.

Keywords Arbuscular mycorrhizal fungus · Enzyme activity $\cdot$ Phosphate-solubilizing fungus $\cdot$ Plant growth Salt stress

\section{Introduction}

Phosphorus $(\mathrm{P})$ is one of the most essential macronutrients limiting plant growth owing to its low bioavailability in soils (Feng et al. 2004; Rodriguez and Fraga 1999). Nevertheless, the repeated and not proper applications of chemical $\mathrm{P}$ fertilizers is expensive and can lead to the loss of soil fertility by disturbing microbial diversity and reducing crops yield (Gyaneshwar et al. 2002a). Consequently, the use of environment-friendly alternative to applications of $\mathrm{P}$ fertilizers is gaining increasing attention (Barea et al. 1997). Phosphorous-solubilizing microorganisms (PSM) are able to replenish soil solution $\mathrm{P}$ by solubilizing insoluble native and applied rock phosphate (Rao 1992; Gyaneshwar et al. 2002b; Khan et al. 2007). Although P-solubilizing bacteria (PSB) have received greater attention than P-solubilizing fungi (PSF), the latter are more effective in solubilizing $\mathrm{P}$ compounds (Kucey 1983; Whitelaw et al. 1997). Moreover, 
PSF do not lose the P dissolving activities upon repeated subculturing under laboratory conditions as the PSB do (Kucey 1983; Rashid et al. 2004).

Approximately $7 \%$ of the global land surface is covered with saline soil (Ruiz-Lozano et al. 1996); the soil salinity is becoming one of the major limiting factors for crop production and an appropriate solution to this situation is to use PSF as bioinoculants. Rietz and Haynes (2003) and Tripathi et al. (2006) had reported that soil microbial communities and their activities are greatly influenced by salinity. Therefore, poor growth and survival of PSF may be a conceivable result. Nevertheless, no information is available on PSF isolated from saline soil.

Arbuscular mycorrhizal fungi (AMF) can form a symbiotic association with most plant species and improve the efficiency of associated plants to assimilate $\mathrm{P}$ from the soil solution (Manjunath et al. 1989; Habte and Osorio 2001). Studies have showed that AMF widely occur in salt environments (Rozema et al. 1986; Wang and Liu 2001) and can improve growth and productivity in both glycophytes and halophytes under salt stress (Asghari et al. 2005; Sannazzaro et al. 2006; Giri et al. 2007). Rodriguez and Fraga (1999) suggested that the inoculated rhizobacteria could release $\mathrm{P}$ ions from insoluble $\mathrm{P}$ sources and the released $\mathrm{P}$ was taken up by the external arbuscular mycorrhizal mycelium because the rhizobacteria cannot transfer $\mathrm{P}$ to roots. Previous studies showed that coinoculation of AMF and PSF could enhance plant biomass, P concentration of plant tissues (e.g., Piccini and Azcon 1987; Singh and Kapoor 1999; Osorio and Habte 2001; Kohler et al. 2007), soil microbial activities (Kohler et al. 2007), and other soil properties (Matiasa et al. 2009). Thus, it is necessary to study the effects of AMF and PSF on microbial activities of saline soil and plant growth for the development of sustainable management of saline soils. To the authors' knowledge, however, there is no information of AMF and PSF combined inoculation in saline soil.

Soil enzyme activities are sufficiently sensitive to perturbations caused by microbial inoculation (Naseby and Lynch 1997), and these measurements can give insights on mineralization of important nutrient elements, such as carbon, nitrogen, and phosphorus (Ceccanti et al. 1994). The measurement of enzyme activities and the integration of the measured activities in a single index can provide information on microbial activity in soil (Nannipieri et al. 2002, 2003). Microorganisms are activated in the rhizosphere soil (Cordier et al. 2000). Therefore, it is important to determine enzyme activities of both rhizosphere and bulk soils, which can affect the concentrations of available $\mathrm{P}$ and other nutrients in soil (Naseby and Lynch 1997; Ceccanti et al. 1994). However, there is no information regarding the use of such parameters for monitoring the ecological impact of AMF and PSF inoculation in saline soil.
Kostelelzkya virginica (L.) Presl. is a perennial herbaceous halophyte native to brackish portions of coastal tidal marshes of the mid-Atlantic and southeastern United States and belongs to the family Malvaceae (Gallagher 1985). In 1992 it was transplanted on the saline land along coastal region of Jiangsu Province by Halophyte Research Lab of Nanjing University, China, to improve coastal tidal flats and develop biomass energy industry (Ruan et al. 2005). A few studies of salinity tolerance, delayed selfing, and plant regeneration of $K$. virginica have been conducted (Blits and Gallagher 1990; Ruan et al. 2009a, b). No information is available on the effects of AMF and PSF on the growth responses of $K$. virginica in saline soil. We have hypothesized that (1) inoculation of AMF and PSF can promote growth of the typical halophyte species (e.g., K. virginica) under salt stress; and (2) inoculated microorganisms can synergistically influence enzyme activities (i.e., invertase, catalase, urease, neutral phosphatase, and alkaline phosphatase) and available $\mathrm{P}$ concentrations of rhizosphere saline soil. To verify these hypotheses, two AMF [Glomus mosseae $(\mathrm{Gm})$ and Glomus aggregatum $(\mathrm{Ga})]$ and one PSF [Mortierella sp. (Ms)], which was isolated from saltaffected coastal soil samples collected from seashore of Jiangsu province, were inoculated in soil-sand culture watered with four levels of salinity.

\section{Materials and methods}

\section{Plant culture}

The experiment was conducted from the beginning of April to the end of December 2009 in a greenhouse at Halophyte Research Lab of Nanjing University $\left(32^{\circ} 30^{\prime} \mathrm{N}\right.$ and $118^{\circ} 42^{\prime} \mathrm{E}$ ), Nanjing, China. The used substrate is a mixture of washed sand and soil $(1: 1, v: v)$, which was sterilized by autoclaving for $1 \mathrm{~h}$ at $121^{\circ} \mathrm{C}$ twice, on two consecutive days and then sieved $(2 \mathrm{~mm})$. Soil was collected from the botanical garden of Nanjing University with the following characteristics: $\mathrm{pH} 7.3$, electrical conductivity (EC) $0.02 \mathrm{dS} \mathrm{m}^{-1}$, organic matter $0.4 \%$, total $\mathrm{N} 13 \mathrm{mg} \mathrm{kg}^{-1}$, available $\mathrm{P} 3 \mathrm{mg} \mathrm{kg}^{-1}$, and extractable potassium (K) $25 \mathrm{mg} \mathrm{kg}^{-1}$. K. virginica was used as the host plant. Plants were grown in a greenhouse under controlled conditions: $16 \mathrm{~h}$ at day light intensity of $220 \mu \mathrm{Em}^{-2} \mathrm{~s}^{-1}$ at $28^{\circ} \mathrm{C}$ and $8 \mathrm{~h}$ night at $18^{\circ} \mathrm{C}$. The relative humidity in the greenhouse during the experiment was $65-85 \%$.

Fungal inocula

Both G. mosseae (Nicol. and Gerd., originated from saline soil of Hebei province, China) and G. aggregatum (originated from saline soil of Hongkong, China) were 
obtained from Bank of Glomales in China. The inocula consisted of spores (1,256 spores per $100 \mathrm{~g}^{-1}$ soil), hyphae, and colonized root fragments, and were collected from a 6-month-old pot culture of G. mosseae and G. aggregatum grown on sorghum in sterile sandy soil.

To prepare liquid inoculum of Mortierella sp., the first step was to activate strains on slants. The fungus was inoculated on solid Martin culture medium $\left(\mathrm{K}_{2} \mathrm{HPO}_{4} 1 \mathrm{~g}\right.$, $\mathrm{MgSO}_{4} \cdot 7 \mathrm{H}_{2} \mathrm{O} 0.5 \mathrm{~g}, \mathrm{NaCl} 11.5 \mathrm{~g}$, peptone $5 \mathrm{~g}$, glucose $10 \mathrm{~g}$, gelose $10 \mathrm{~g}, 1 / 30,000$ Bengal red water solution $100 \mathrm{ml}$, and demineralized water $900 \mathrm{ml}$ ), which had been autoclaved for $30 \mathrm{~min}$ at $121^{\circ} \mathrm{C}$ and then cultured in the dark at $28^{\circ} \mathrm{C}$ for 4 days. After activation, $3 \mathrm{ml}$ sterile water was added to test tube, and then the mixture was poured into $50 \mathrm{ml}$ Martin broth (MB) which was added to $1.15 \% \mathrm{NaCl}$; Mortierella sp. was grown on a rotating shaker at $180 \mathrm{rpm}$ for $48 \mathrm{~h}$, and this was the starter culture. It was added $(5 \%$ of volume) to $\mathrm{MB}$ and then we added $1.15 \% \mathrm{NaCl}$, and the $\mathrm{MB}$ was cultured on a shaker for $96 \mathrm{~h}$ at $180 \mathrm{rpm}$. At the end it contained $2.3 \times 10^{5}$ colony forming units $\mathrm{mL}^{-1}$ and the solution was stored at $4^{\circ} \mathrm{C}$ until use.

\section{Experimental design and biological treatments}

To study the effects of AMF and PSF on $K$. virginica under salt stress, the seedlings of $K$. virginica were watered with $\mathrm{NaCl}$ solutions. The experimental design was full factorial, with four salinity levels $(0,100,200$, and $300 \mathrm{mM}) \times$ eight microbial treatments: inoculated with $10 \mathrm{~g}$ of $\mathrm{Gm}$, inoculated with $10 \mathrm{~g}$ of $\mathrm{Ga}$, inoculated with $10 \mathrm{ml}$ of $\mathrm{Ms}$, inoculated with $5 \mathrm{~g}$ of $G$. mosseae and $5 \mathrm{~g}$ of $G$. aggregatum $(\mathrm{Gm}+\mathrm{Ga})$, inoculated with $10 \mathrm{~g}$ of $\mathrm{G}$. mosseae and $10 \mathrm{ml}$ of Mortierella sp. $(\mathrm{Gm}+\mathrm{Ms})$, inoculated with $10 \mathrm{~g}$ of G. aggregatum and $10 \mathrm{ml}$ of Mortierella sp. (Ga+ $\mathrm{Ms}$ ), inoculated with $5 \mathrm{~g}$ of $G$. mosseae and $5 \mathrm{~g}$ of $G$. aggregatum and $10 \mathrm{ml}$ of Mortierella sp. $(\mathrm{Gm}+\mathrm{Ga}+\mathrm{Ms})$, and no inoculated control (CK). Each treatment was replicated three times in a randomized block design and each replicate had three plants.

On April 3, 2009, seeds of $K$. virginica were surfacesterilized by soaking in $5 \% \mathrm{NaOCl}$ solution for $10 \mathrm{~min}$ and rinsed with sterile distilled water. They were then transferred aseptically to petri dishes filled with water and incubated for 4 days at $25^{\circ} \mathrm{C}$. One week after germination, seedlings of uniform size were transferred to pots (diameter $15 \mathrm{~cm}$, height $15 \mathrm{~cm}$ ) filled with $900 \mathrm{~g}$ sterilized sandy soil; each pot had three seedlings. According to the design, $10 \mathrm{~g}$ mycorrhizal inoculum or/and $10 \mathrm{ml}$ Mortierella sp. were placed in soil below the $K$. virginica seedlings prior to planting. Meanwhile, $10 \mathrm{~g}$ mycorrhizal inoculum and $10 \mathrm{ml} \mathrm{Ms}$ inoculum, both autoclaved at $121^{\circ} \mathrm{C}$ for $90 \mathrm{~min}$ three times, were added to control pots. Each pot was put on a 2-cm-deep plate and incubated in greenhouse on April 10, 2009.
Plants were irrigated with water for 4 weeks. Then, pots were watered by a modified (all nutrient solutions without P) solution of Hoagland and Arnon (1950). For the salinity treatments, $\mathrm{NaCl}$ (Fisher ACS) was added to the Hoagland nutrient solution to give final $\mathrm{NaCl}$ concentrations of 0 , 100,200 , and $300 \mathrm{mM}$, respectively. The salt concentration is within the range of the habitat of $K$. virginica, which extends from Louisiana to Florida and along the Atlantic Coast to Delaware (Blits and Gallagher 1990). The pH of the nutrient solution for all treatments was 7.2. All nutrient solutions were prepared using demineralized water. Plants were watered with $25 \mathrm{ml} \mathrm{NaCl}$ solution at 3-day intervals for 24 days. The soil was salinized stepwise to avoid osmotic shock. The leachate was collected and added back to soil to maintain the salinity near the target level; distilled water was added as necessary to maintain soil moisture.

\section{Soil samples collection}

After 90 days, according to Riley and Barber $(1969,1970)$, whole plants were extracted from pots. The soil obtained by gently shaking roots and collected in sterilized culture dish was considered "bulk soil." The rest soil that adhered to roots was then collected in another sterile culture dish and termed "rhizosphere soil." Soil samples were divided into two parts; one part was stored at $4^{\circ} \mathrm{C}$ for biological and biochemical analyses and the other was air-dried at room temperature for chemical analysis.

\section{Plant analyses}

All shoots tissues were dried in a forced-air oven at $80^{\circ} \mathrm{C}$ for $72 \mathrm{~h}$ for biomass determination. Shoot biomass was the sum of leaves and stems. The fresh root mass of six plants was used for determining root dry weight. To assess AMF colonization, roots from three plants were cleared with $10 \%$ $\mathrm{KOH}$ and stained with $0.05 \%$ trypan blue (Phillips and Hayman 1970). The percentage of root length colonized by AMF was calculated as reported by Mcgonigle et al. (1990). The roots were cut into $1-\mathrm{cm}$ segments, and 30 fragments were examined for AMF colonization by a compound microscope (100 magnifications). Positive counts for AMF colonization included the presence of vesicles, arbuscules or typical mycelium.

Soil chemical, biological, and biochemical analysis

The available $\mathrm{P}$ concentration of soil was determined using the sodium bicarbonate-extractable $\mathrm{P}$ colorimetric method (Olsen et al. 1954). Soil pH value was measured using a glass electrode and a soil to water ratio of 1:2.5 (Dick et al. 2000). EC of soil was measured with a conductivity meter (Model DDS-11A; Leizi, Shanghai, China). The pour-plate 
technique was applied for estimation of Ms populations in soil (Pikovskaya 1948). The activities of soil invertase (E. C. 3.2.1.26), catalase (E.C. 1.11.1.6), urease (E.C. 3.5.1.5), and phosphatase (E.C. 3.1.3.2) were determined according to Ohshima et al. (2007), Trasar-Cepeda et al. (1999), Nannipieri et al. (1980), and Kandeler et al. (1999), respectively. The activities of soil enzymes were assayed within 1 week after sampling.

\section{Statistical analysis}

All data were statistically analyzed by analysis of variance using the SPSS software package (SPSS 10.0 for Windows 2001 ) and means separated by Duncan test at $p$ values $<0.05$.

\section{Results}

\section{AM colonization}

Structures characteristic of AMF were not observed in roots of controls and plants inoculated with Ms alone (data not shown). Plants inoculated with Ga alone showed significantly higher root colonization (41.6\%) than plants only inoculated with $\mathrm{Gm}(30 \%)$ at $100 \mathrm{mM} \mathrm{NaCl}$, while there was an opposite result at $300 \mathrm{mM} \mathrm{NaCl}(p<0.05$, Fig. 1a). Except for $0 \mathrm{mM} \mathrm{NaCl}$, the root colonization of plants co-inoculated with AMF ( $\mathrm{Gm}$ and/or $\mathrm{Ga}$ ) and Ms was significantly higher than plants inoculated with AMF alone $(p<0.05)$. Plants inoculated with $\mathrm{Gm}$ and Ms showed significantly higher root colonization $(59.6 \%$ and $46 \%$ ) than those inoculated with $\mathrm{Ga}$ and Ms (45.7\% and 36.7\%) and those inoculated with the three fungi $(50.2 \%$ and $38 \%$ ) at 200 and $300 \mathrm{mM} \mathrm{NaCl}$, respectively. The percentages of root colonization declined by increasing salinity level $(p<0.05$, Fig. 1a).

\section{Ms populations}

Both rhizosphere and bulk soils of plants inoculated with $\mathrm{Gm}$ and Ms showed significantly higher Ms populations than soils of other plants $(p<0.05)$ at each salinity level (Fig. 1b, c). Rhizosphere soil of plants inoculated with three fungi showed significantly lower Ms populations than rhizosphere soil of plants inoculated with AMF and Ms $(p<0.05$, Fig. 1c). The highest Ms populations were presented in rhizosphere and bulk soils of plants inoculated with $\mathrm{Gm}$ and $\mathrm{Ms}$ at $100 \mathrm{mM} \mathrm{NaCl}$.

Plant growth

At all levels of salinity, shoot and root dry weights of plants inoculated with AMF and/or Ms were higher than those of control plants. Root dry weights of plants inoculated with
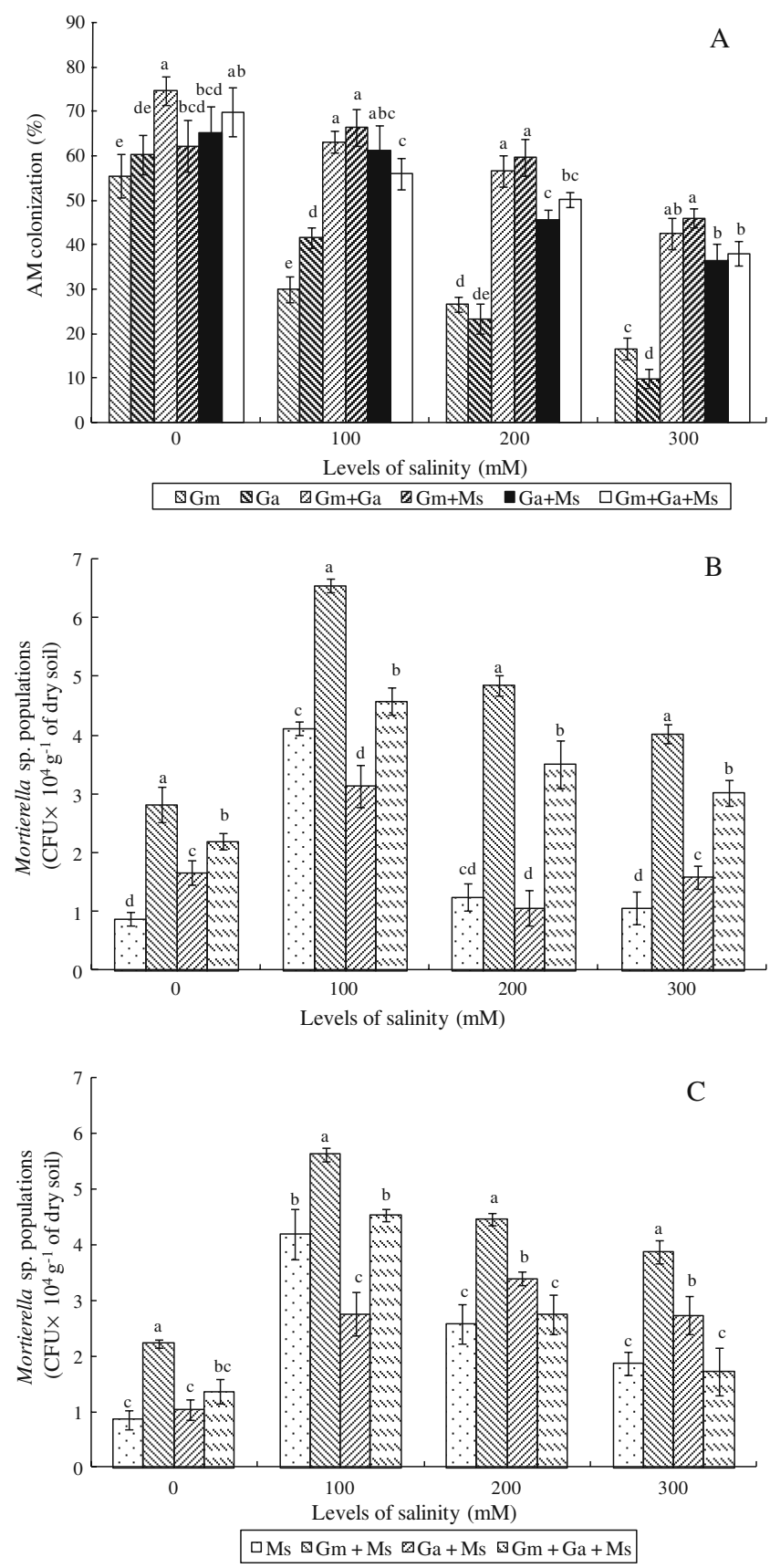

Fig. 1 Effects of arbuscular mycoorihzal fungi and P-solubilizing fungus (Mortierella sp.) on AM colonization (a), Mortierella sp. populations of bulk soil (b), and rhizosphere soil (c) at different salinities. Data are means \pm SE of three replicates. Means followed by the same letter are not significantly different at the same salinity level $(p<0.05)$ as determined by Duncan test

Ga alone were significantly higher than those of plants inoculated with $\mathrm{Gm}$ at 0 and $100 \mathrm{mM} \mathrm{NaCl}$, while an opposite result was observed at 200 and $300 \mathrm{mM} \mathrm{NaCl}(p<$ 0.05 , Fig. 2b). The inoculation of Ms significantly improved positive effects of AMF ( $\mathrm{Gm}$ or $\mathrm{Ga}$ ) on shoot and root dry weights under salt stress (i.e., 100, 200, and $300 \mathrm{mM} \mathrm{NaCl}$, as well as below; $p<0.05$, Fig. 2a, b). 

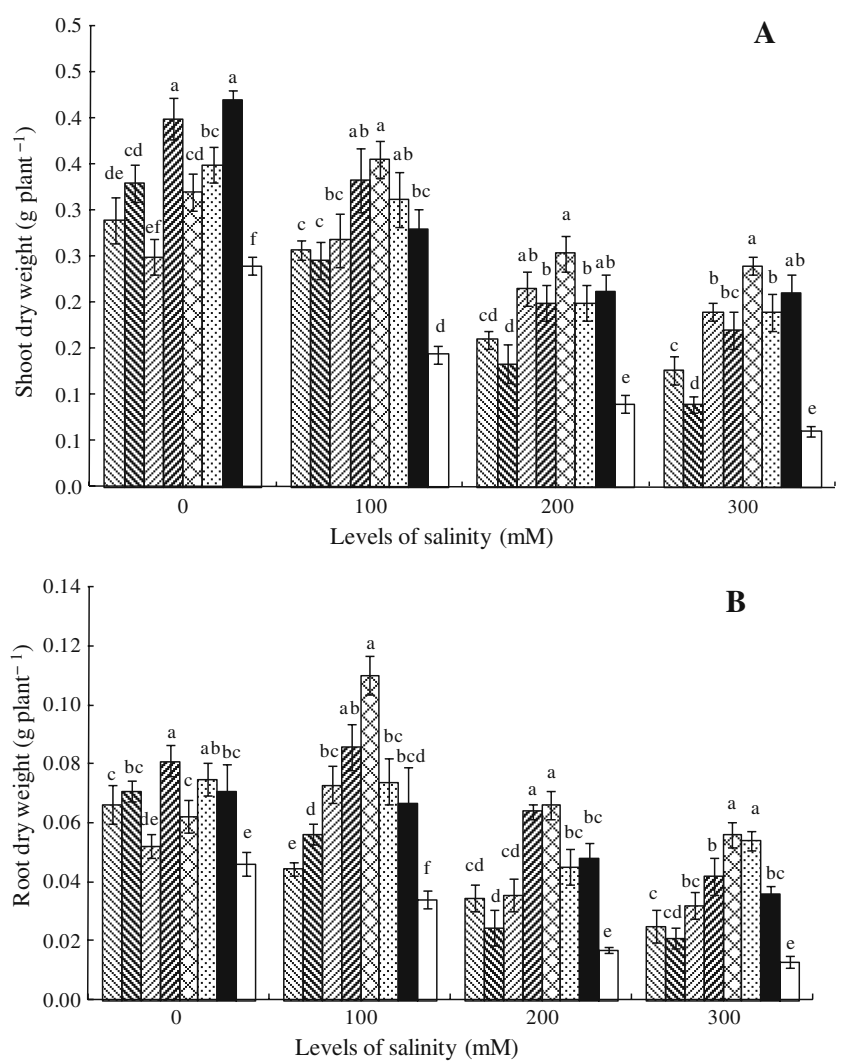

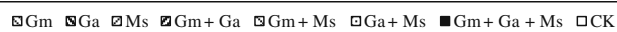

Fig. 2 Effects of arbuscular mycoorihzal fungi and P-solubilizing fungus (Mortierella sp.) on shoot dry weight (a) and root dry weight (b) at different salinities. Data are means \pm SE of three replicates. Means followed by the same letter are not significantly different at the same salinity level $(p<0.05)$ as determined by Duncan test

Inoculation with $\mathrm{Gm}$ and $\mathrm{Ms}$ showed significant higher plant biomass than inoculation of $\mathrm{Ga}$ and $\mathrm{Ms}$ (e.g., shoot dry weights at 200 and $300 \mathrm{mM} \mathrm{NaCl}$ and root dry weights at 100 and $200 \mathrm{mM} \mathrm{NaCl}, p<0.05)$.

\section{Soil enzyme activities}

All inoculation treatments enhanced urease activities of soils with respect to noninoculated controls at all salinity levels $(p<0.05$, Fig. 3a, b). Mortierella sp. significantly increased urease activities of rhizosphere soil when inoculated alone or with dual AMF under salt stress $(p<0.05$, Fig. 3b). Urease activities increased from 0 to $100 \mathrm{mM}$ $\mathrm{NaCl}$, and then decreased from 100 to 200 and $300 \mathrm{mM}$ $\mathrm{NaCl}$.

Except for inoculation with $\mathrm{Gm}$ and Ms, the combined inoculations enhanced invertase activities of all soils with respect to those of controls. In all soils, Ms decreased the positive effects of AMF on invertase activities, and invertase activity showed the lowest values in each salinity level in the $\mathrm{Gm}$ and Ms treatment $(p<0.05$; Fig. 3c, d).
Invertase activities showed a trend similar to that of urease activities under salt stress.

All inoculation treatments at all salinity levels $(p<0.05)$ significantly increased neutral and alkaline phosphatase activities of both soils with respect to controls (Fig. 3e-h). Mortierella sp. significantly increased the positive effects of AMF on neutral phosphatase activity at all salinity levels $(p<0.05)$.

Catalase activities were reduced by increasing salinity; and those of both bulk and rhizosphere soils of inoculated with AMF and/or Ms were significantly higher than those of controls at all salinity levels $(p<0.05$; Fig. $3 \mathrm{i}, \mathrm{j})$. Mortierella sp. significantly enhanced the positive effects of $\mathrm{Gm}$ at $300 \mathrm{mM} \mathrm{NaCl}, \mathrm{Ga}$ at 0 and $300 \mathrm{mM} \mathrm{NaCl}$, and $\mathrm{Gm}$ plus $\mathrm{Ga}$ at 200 and $300 \mathrm{mM} \mathrm{NaCl}$ on catalase activities in bulk soil whereas it had no effect in rhizosphere soil $(p<0.05$, Fig. 3i).

Available P concentrations

Except for $0 \mathrm{mM} \mathrm{NaCl}$, single inoculation with $\mathrm{Ms}$ significantly increased available $\mathrm{P}$ concentrations of all soils with respect to single inoculation with AMF and controls $(p<0.05$; Fig. $4 \mathrm{a}, \mathrm{b})$. In all soils at each salinity level, inoculation with $\mathrm{Gm}$ and Ms significantly increased available $\mathrm{P}$ concentrations with respect to single inoculation with $\mathrm{Gm}$ or Ms and dual inoculation with $\mathrm{Ga}$ and $\mathrm{Ms}$ $(p<0.05)$. The highest available $\mathrm{P}$ concentrations were recorded when plants were inoculated with $\mathrm{Gm}$ and $\mathrm{Ms}$ at $100 \mathrm{mM} \mathrm{NaCl}$. Bulk soils from treatments involving triple inoculation had significantly higher available $\mathrm{P}$ concentrations than those of dual inoculation with $\mathrm{Ga}$ and Ms. Similar results were observed in rhizosphere soil only at $100 \mathrm{mM} \mathrm{NaCl}(p<0.05)$.

\section{Soil $\mathrm{pH}$ and electricity conductivity}

Except for the $300 \mathrm{mM} \mathrm{NaCl}$ treatment, in bulk soil, plants inoculated with $\mathrm{Gm}$ and Ms showed significantly lower $\mathrm{pH}$ values than those of other treated soils $(p<0.05$, Fig. 5a). The pH values of all inoculated soils were lower than those of control soils at each salinity level (Fig. 5a, b). The $\mathrm{pH}$ values of rhizosphere soil declined by increasing salinity.

Electrical conductivities of all rhizosphere or bulk soil were significantly higher than those of control soils at all salinity level ( $p<0.05$; Fig. $5 \mathrm{c}, \mathrm{d})$. The highest EC values of soils were recorded when plants were inoculated with $\mathrm{Gm}$ and Ms at all salinity level. For all salinity treatments, bulk soil of plants inoculated with Ms showed significantly lower EC values than those of other inoculated soils $(p<0.05$, Fig. 5c). A similar effect was observed in rhizosphere soil. 

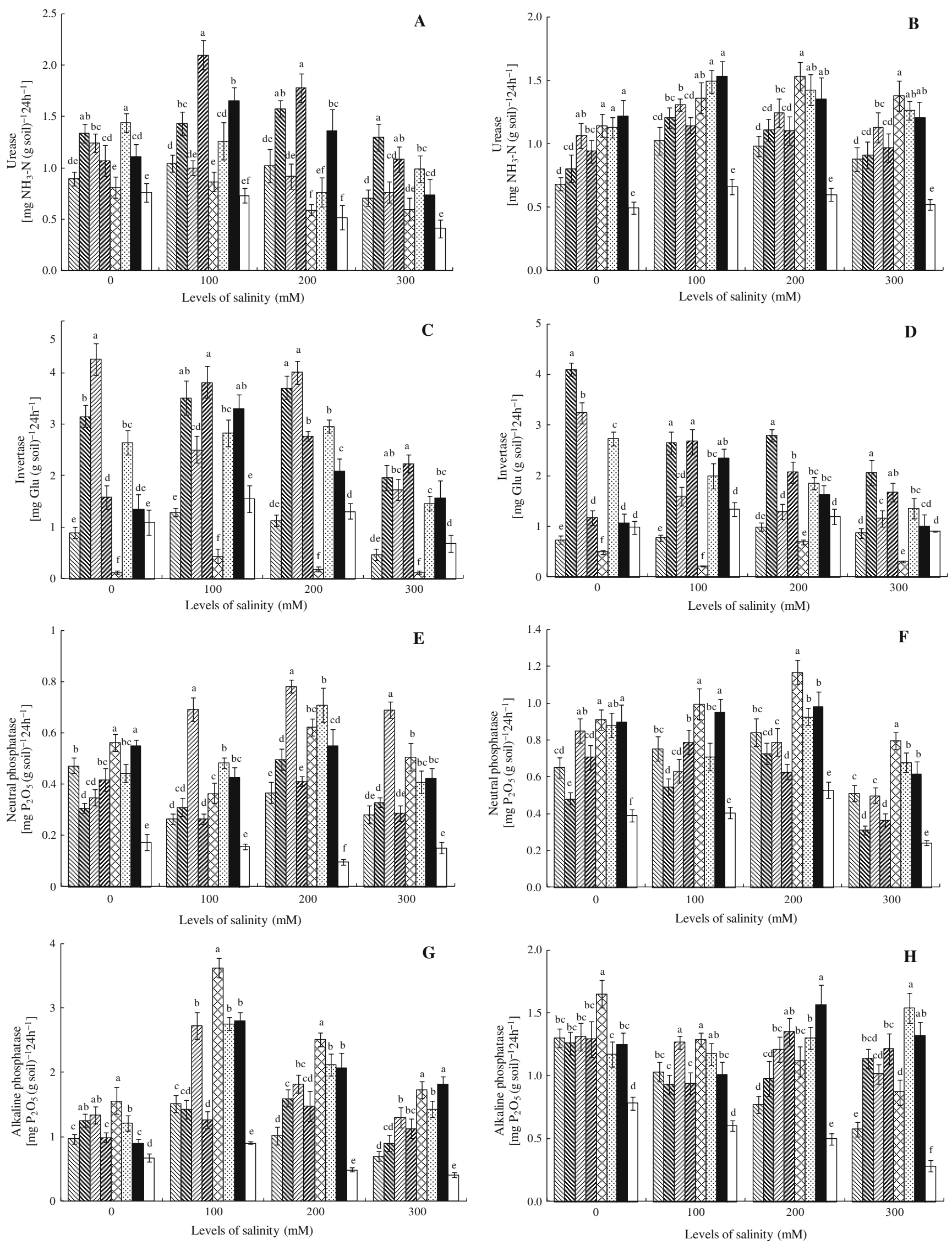
Fig. 3 Effects of arbuscular mycorrhizal fungi and P-solubilizing fungus (Mortierella sp.) on soil enzyme activities at different salinities. Urease (a), invertase (c), neutral phosphatase (e), alkaline phosphatase (g), and catalase (i) activities of bulk soil; urease (b), invertase (d), neutral phosphatase (f), alkaline phosphatase (h), and catalase (j) activities of rhizosphere soil. Data are means \pm SE of three replicates. Means followed by the same letter are not significantly different at the same salinity level $(p<0.05)$ as determined by Duncan test

\section{Discussion}

Interaction between $\mathrm{AMF}$ and $\mathrm{Ms}$ under salt stress

Mycorrhizal symbiosis acts as a key component in helping plants to cope with adverse environmental condition (Giri et al. 2003), but the addition of various salts to soils inhibits hyphal growth with a subsequent decrease in the mycorrhizal colonization of plants (Ruiz-Lozano and Azcón 2000). We have shown that salt stress significantly inhibited AMF colonization of $K$. virginica roots, probably because salt inhibited germination of AMF spore (Figs. 1 and 6), colonization of the plant roots by the fungi and formation of functional mycorrhizal structures within the roots (Juniper and Abbott 2006). The mycorrhizal root colonization under salt stress promoted by combined inoculation of AMF and Ms, confirmed the finding of Garbaye and Bowen (1987) in Pinus radiate. The enhanced mycorrhizal root colonization by inoculation with Ms may be attributed to phytohormone production to the increase of soil soluble $\mathrm{P}$ promoted by Ms in saline soil (Figs. 2 and 6, Jacobsen et al. 1992; Toro et al. 1996). Inoculation with AMF and Ms also significantly increased Ms populations of soil, probably because mycorrhized plants released carbonaceous substances used as a C source by PSM in the rhizosphere soil (Linderman 1988; Azcon and Barea 1996; Singh and Kapoor 1999). However, plants inoculated with three fungi showed significantly lower mycorrhizal colonization and Ms pop-
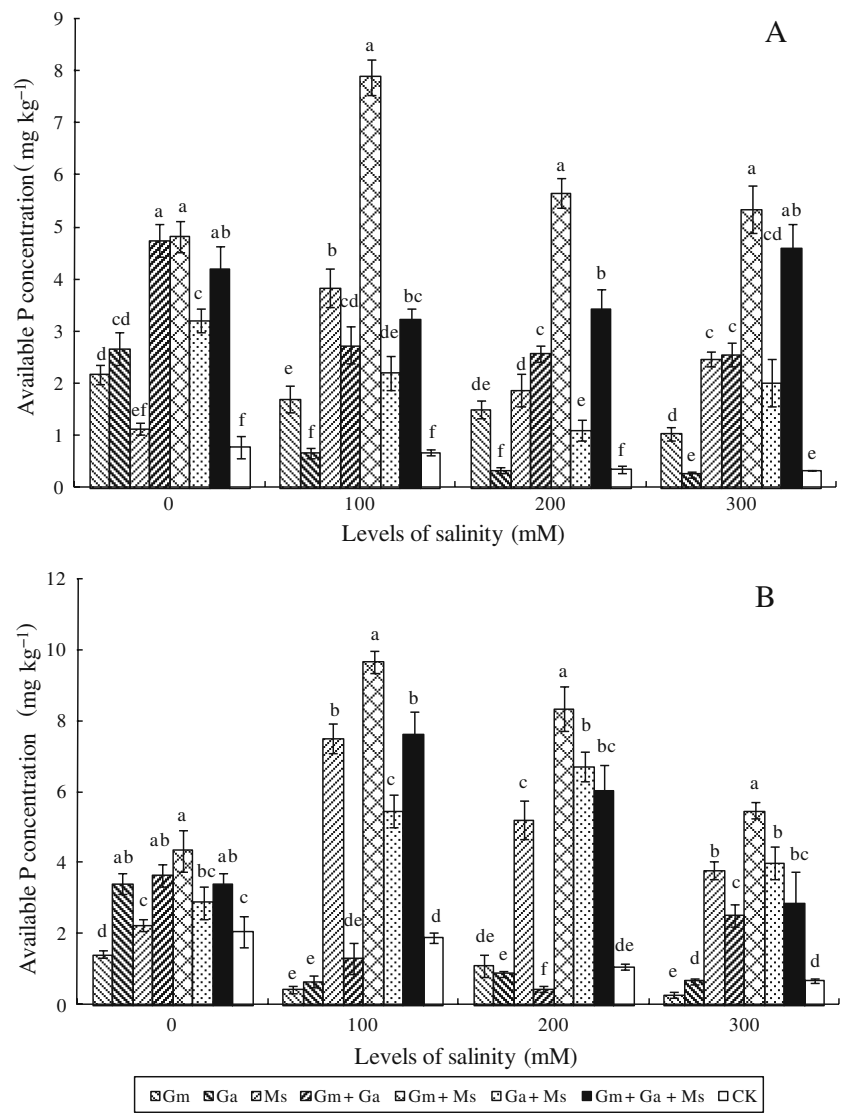

Fig. 4 Effects of arbuscular mycorrhizal fungi and P-solubilizing fungus (Mortierella sp.) on available P concentrations in bulk soil (a) and rhizosphere soil (b) at different salinities. Data are means $\pm \mathrm{SE}$ of three replicates. Means followed by the same letter are not significantly different at the same salinity level $(p<0.05)$ as determined by Duncan test

ulations in rhizosphere soil than plants inoculated with $\mathrm{Gm}$ and Ms. This may be due to the competition among microorganisms for root exudates or nutrients under salt stress. It is important to underline that the used method for
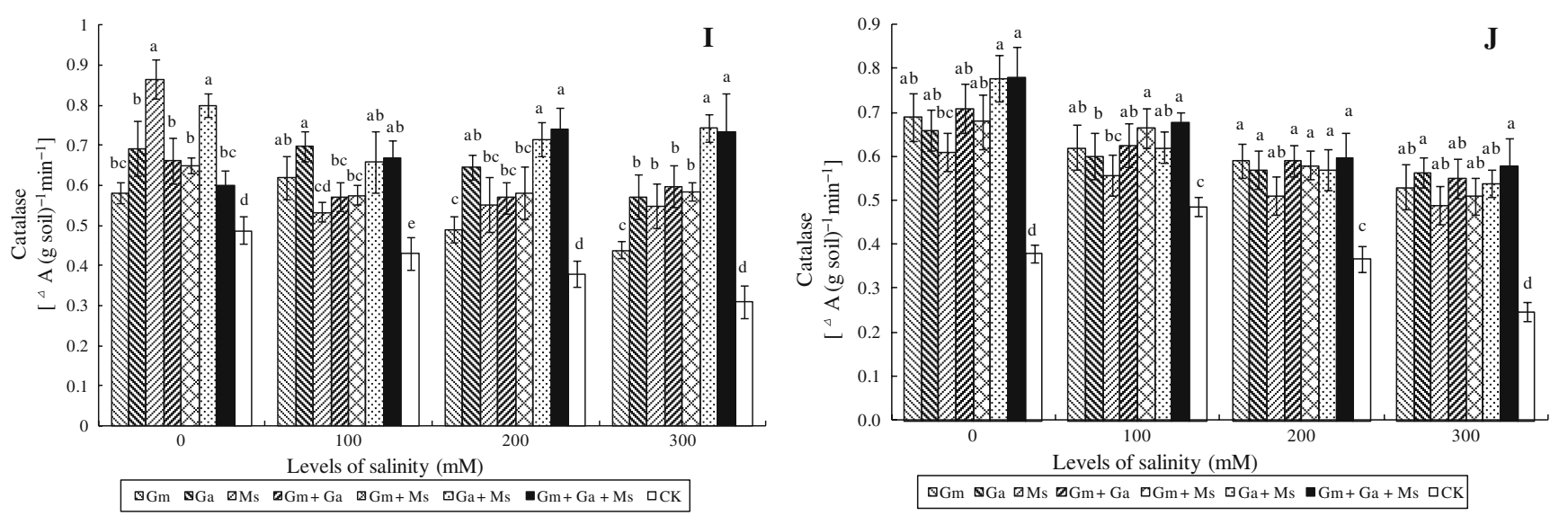

Fig. 3 (continued) 

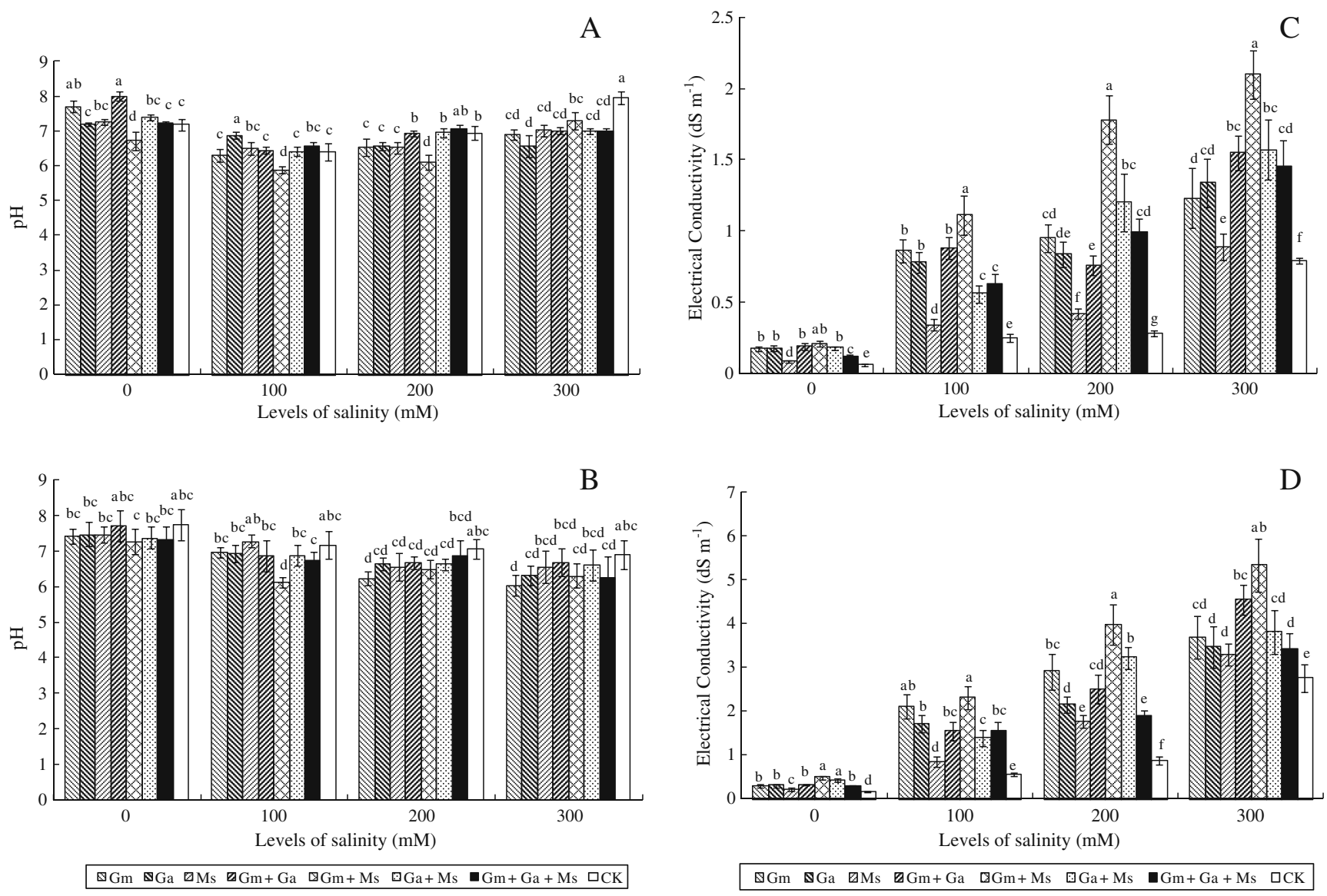

Fig. 5 Effects of arbuscular mycorrhizal fungi and P-solubilizing fungus (Mortierella sp.) on $\mathrm{pH}$ and electrical conductivity of soil at different salinities. $\mathrm{pH}$ (a) and electrical conductivity (c) of bulk soil; $\mathrm{pH}$ (b) and electrical conductivity (d) of rhizosphere soil. Data are

means \pm SE of three replicates. Means followed by the same letter are not significantly different at the same salinity level $(p<0.05)$ as determined by Duncan test

isolating PSM and determining Ms populations is based on the use of tricalcium phosphate (Pikovskaya 1948), and this method has been criticized by Collavino et al. (2010).

Effect of inoculation on plant growth under salt stress

Inoculation with $\mathrm{AMF}$ improves growth of plants under a variety of salt stress conditions (Al-Karaki et al. 2001; Giri et al. 2003; Sannazzaro et al. 2006). We have observed the same for shoot and root dry weights of $K$. virginica inoculated with AMF and/or Ms at all salinity levels. The dual inoculation with AMF and PSF had positive effects on alfalfa (Piccini and Azcon 1987), wheat (Singh and Kapoor 1999), and Lactuca sativa (Kohler et al. 2007). Osorio and Habte (2001) suggested a synergistic interaction between PSM and AMF. Although Ga had higher colonization rates than $\mathrm{Gm}$ at $100 \mathrm{mM} \mathrm{NaCl}$, plants inoculated with $\mathrm{Gm}$ showed a better resistance to salt stresses than those colonized by Ga. This may partly explain why the highest shoot and root biomasses were obtained when plants were inoculated with Ms and $\mathrm{Gm}$. Plants inoculated with three

fungi had significantly lower root dry matter than plants inoculated with $\mathrm{Gm}$ and Ms, probably due to the lower mycorrhizal root colonization of the former plants. However, inoculation of AMF and Ms may increase root development and nutrient uptake, and this may decrease root/shoot ratios (Kothari et al. 1990; Berta et al. 1995).

Changes of soil enzyme activities with inoculation under salt stress

Eizavi and Tabatabai (1977) had reported that acid phosphatase is predominant in acid soils and alkaline phosphatase is predominant in alkaline soils. Therefore, we have only determined neutral and alkaline phosphatase activities since soil $\mathrm{pH}$ was 7.3. Catalase (Frankenberger and Bingham 1982), alkaline phosphatase (Garcia and Hernandez 1996), invertase, and urease (Omar et al. 1994) activities were inhibited by increasing soil salinity. Similarly, we have observed that soil enzyme activities of control soil decreased proportionately by increasing salinity. The reduced enzyme activities may depend on the 


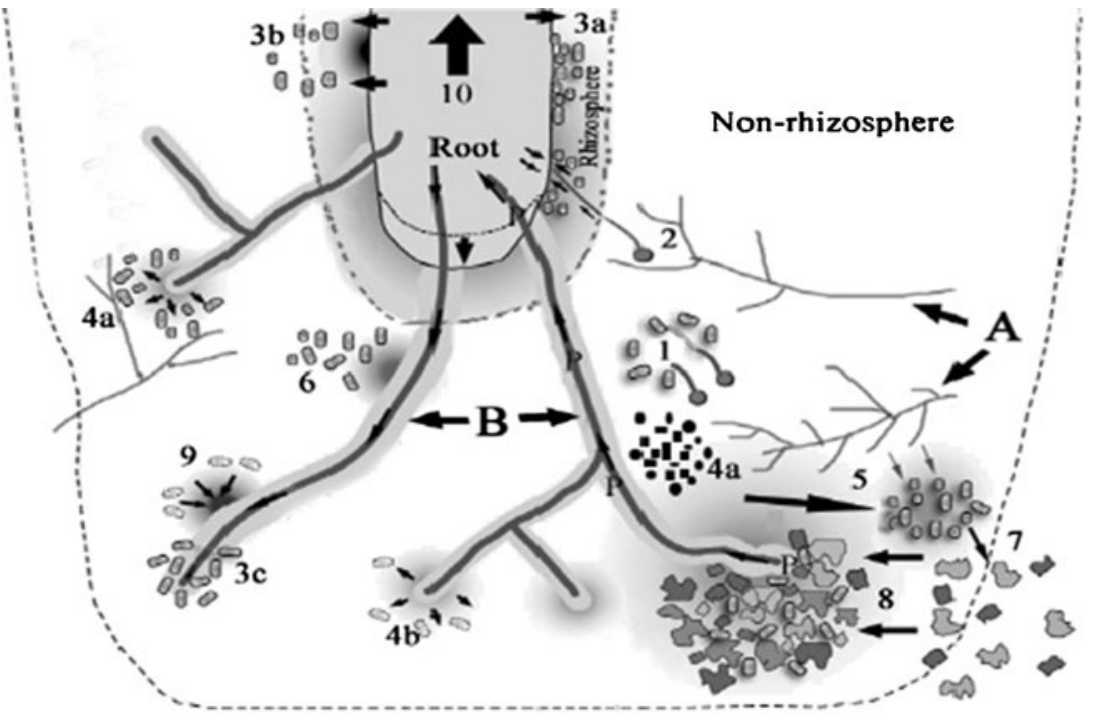

Fig. 6 Schematic view of possible mechanism of co-inoculation of AMF and P-solubilizing fungus in saline soil. $A$ hyphae of Mortierella sp.; $B$ hyphae of AMF; 1 inhibition of salt on AMF growth and colonization; 2 promotion of Mortierella sp. on AMF growth and colonization; 3 changes in root structure: $3 a$ stimulatory or $3 b$ inhibitory compounds present in root exudation, $3 c$ supply of

decrease in enzyme synthesis due to the decrease in abundance and activity of soil microorganisms and/or to the "salting-out" effects on enzyme proteins (Omar et al. 1994). Microbial inoculation promoted neutral phosphatase, alkaline phosphatase, urease, and catalase activities in both bulk and rhizosphere soils (Figs. 5 and 6). Dodd et al. (1987) and Ezawa and Yoshida (1994) also showed that phosphatase activities of rhizosphere soil of AMF colonized plants were higher than those of rhizosphere soil of noncolonized plants. Microbial inoculation may alleviate the negative effects of increasing concentration of salt solutions on enzyme activities, probably because both AMF (Allen et al. 1981) and Ms inoculations increased soil microbial biomass. However, further research is required to understand the relative mechanisms.

In bulk soil, inoculation with Ms significantly increased the positive effects of AMF on neutral phosphatase, alkaline phosphatase, and catalase activities under salt stress, while invertase and urease activities were reduced. The effects of AMF on neutral phosphatase and urease activities were enhanced by Ms inoculations in rhizosphere soil, but reduced on invertase activities. It is difficult to explain the different responses of enzyme activities of bulk and rhizosphere soils inoculated with PSF and AMF, because the measured enzyme activities depend on the contribution of both extracellular and intracellular enzyme activities (Nannipieri et al. 2003), and stable extracellular enzyme activities are associated with soil colloids and persist even in harsh environments that would limit intracellular microbiological activity (Nannipieri et al. 2002). energy-rich carbohydrates via AM fungi hyphae; 4 promotion $(4 a)$ or inhibition $(4 b)$ of microbial activity; 5 stimulation of soil enzyme activities; $6 \mathrm{pH}$ changes; 7 effects on insoluble $\mathrm{P} ; 8$ uptake of soluble P; 9 uptake of other nutrients; 10 stimulation of plant (Fig. 5 is modified from Jonas et al. 2004)

Osorio and Habte (2001) reported that acid production was the major mechanism in the solubilization of rock phosphate by the $\mathrm{Ms}$, and the $\mathrm{pH}$ value of the growth medium decreased as a result of acid production by PSM [Fig. 6 (6)]. We have shown that $\mathrm{pH}$ values of all inoculation treatments were lower than those of controls at each salinity level. Soil enzyme activities can be increased, decreased, or not affected by soil acidity (Kang and Freeman 1999; Acosta-Martinez and Tabatabai 2000). In addition, AMF can modify quantity and quality of root exudation (Mar et al. 2000).

\section{Changes of available $\mathrm{P}$ concentrations and electricity conductivity with inoculation}

Arbuscular mycorrhizal fungi can absorb $\mathrm{P}$ from the soil solution, as plant roots do, and there is no evidence of their ability to solubilize insoluble soil P minerals (Bolan 1991; Cardoso et al. 2006). However, we have shown that inoculation with $\mathrm{Gm}$ significantly increased available P concentrations in bulk soil and we are not able to explain the relative mechanisms. As discussed before, the use of tricalcium phosphate for determining PSF or PSB has been criticized (Collavino et al. 2010). The type of phosphate, the analytical procedure for determining the solubilized $\mathrm{P}$, the incubation conditions, and medium are all important factors affecting P solubilization (Ogut et al. 2010). Soils inoculated with $\mathrm{Gm}$ and $\mathrm{Ms}$ had significantly higher available $\mathrm{P}$ concentrations than soils only inoculated with Gm or Ms. Probably, the effectiveness of inoculated PSF 
can be stimulated by the mycorrhiza (Tarafdar and Marschner 1995; Osorio and Habte 2001). The P solubilization occurs in the rhizosphere soil where organic compounds are released by roots or mycorrhizae (Nguyen 2003; Amos and Walters 2006). Many rhizosphere microorganisms are heterotrophs and might use these organic substrates to produce organic acids, which would increase $\mathrm{P}$ concentrations in solution (Hameeda et al. 2006; Reyes et al. 2006). Probably $\mathrm{Gm}$ was more effective than $\mathrm{Ga}$ in stimulating P solubilization by Ms, but we are unable to explain the underlying mechanisms. When plants were inoculated with three fungi, however, there were no significant effects on available P concentrations in rhizosphere soil. Probably, changes in quantities and compositions of rhizodepositions and microbial secretions, which would affect the activities of PSM in solubilizing insoluble inorganic or organic phosphate, were responsible for the different response with three inoculants. Single inoculation with Ms did not significantly increase available $\mathrm{P}$ concentrations of the bulk and rhizosphere soils compared to single inoculation with AMF at $0 \mathrm{mM} \mathrm{NaCl}$. Probably, Ms was not activated by the nonsaline conditions, being isolated from saline soil of seashore. The result that the highest Ms populations were observed at $100 \mathrm{mM} \mathrm{NaCl}$ indirectly confirms the above assumption. It is conceivable that $100 \mathrm{mM} \mathrm{NaCl}$ was the most effective saline treatment in stimulating Ms activities.

All inoculation treatments significantly enhanced soil EC. On the contrary, Giri et al. (2003) and Buwalda et al. (1983) reported that inoculation of mycorrhiza significantly reduced soil EC. Our results can depend on the fact that mycorrhized plants decreased the uptake of $\mathrm{Na}$ (Al-Karaki 2006; Colla et al. 2008).

\section{Conclusion}

The dual inoculation of arbuscular mycorrhizal fungi and Mortierella sp. significantly affected plant growth, but the triple inoculation was less effective. The increased enzyme activities and available $\mathrm{P}$ of soil after inoculation with arbuscular mycorrhizal fungi and Mortierella sp. may alleviate the negative effects of increasing salinity on plant growth. To obtain the maximum benefit for plant growth, it is needed to select the right combination of arbuscular mycorrhizal fungi species and phosphorous-solubilizing microorganisms to be inoculated in saline soils. However, further research is needed to understand the underlying mechanisms.

Acknowledgments This research was supported by 11.5 National Key Technology R\&D Program of China (2006BAD09A04; 2006BAD09A08). We would like to thank Prof. Youshan Wang of Bank of Glomales in China for providing the arbuscular mycorrhizal fungi. We are grateful to Dr. Ming Nie of Nanchang University and three anonymous referees for their helpful comments.
Open Access This article is distributed under the terms of the Creative Commons Attribution Noncommercial License which permits any noncommercial use, distribution, and reproduction in any medium, provided the original author(s) and source are credited.

\section{References}

Acosta-Martinez V, Tabatabai MA (2000) Enzyme activities in a limed agricultural soil. Biol Fertil Soils 31:85-91

Al-Karaki GN (2006) Nursery inoculation of tomato with arbuscular mycorrhizal fungi and subsequent performance under irrigation with saline water. Sci Hortic 109:1-7

Al-Karaki GN, Hammad R, Rusan M (2001) Response of two tomato cultivars differing in salt tolerance to inoculation with mycorrhizal fungi under salt stress. Mycorrhiza 11:43-47

Allen MF, Sexton JC, Jr-Moore TS, Christensen M (1981) Influence of phosphate source on vesicular-arbuscular mycorrhizae of Bouteloua gracilis. New Phytol 87:687-694

Amos B, Walters DT (2006) Maize root biomass and net rhizodeposited carbon: an analysis of the literature. Soil Sci Soc Am J 70:1489-1503

Asghari HR, Marschner P, Smith SE, Smith FA (2005) Growth response of Atriplex nummularia to inoculation with arbuscular mycorrhizal fungi at different salinity levels. Plant Soil 273:245-256

Azcon C, Barea JM (1996) Interactions of arbuscular mycorrhiza with rhizosphere microorganisms. In: Guerrero E (ed) Mycorrhiza. Biological soil resource. FEN, Bogota, pp 47-68

Barea JM, Azcón-Aguilar C, Azcón R (1997) Interactions between mycorrhizal fungi and rhizosphere microorganisms within the context of sustainable soil-plant systems. In: Gange AC, Brown VK (eds) Multitrophic interactions in terrestrial systems. Blackwell Science, Cambridge, pp 65-77

Berta G, Trotta A, Fusconi A, Hooker JE, Munro M, Atkinson D, Giovannetti M, Morini S, Fortuna P, Tisserant B, GianinazziPearsonI V, Gianinazzi S (1995) Arbuscular mycorrhizal induced changes to plant growth and root system morphology in Prunus cerasifera. Tree Physiol 15:281-293

Blits KC, Gallagher JL (1990) Salinity tolerance of Kostelelzkya virginica II. Root growth, lipid content, iron and water relations. Plant Cell Environ 13:419-425

Bolan NS (1991) A critical review on the role of mycorrhizal fungi in the uptake of phosphorus by plants. Plant Soil 134:189-207

Buwalda JG, Stribley DP, Tinker PB (1983) Increased uptake of anions by plants with vesicular arbuscular mycorrhizas. Plant Soil 71:467-469

Cardoso I, Boddington CL, Janssen BH, Oenema O, Kuyper T (2006) Differential access to phosphorus pool of an oxisol by mycorrhizal and non-mycorrhizal maize. Commun Soil Sci Plant Anal 37:1537-1552

Ceccanti B, Pezzarossa B, Gallardo-Lancho FJ, Masciandaro G (1994) Bio-tests as markers of soil utilization and fertility. Geomicrobiol J 11:309-316

Colla G, Rouphael Y, Cardarelli M, Tullio M, Rivera CM, Rea E (2008) Alleviation of salt stress by arbuscular mycorrhizal in zucchini plants grown at low and high phosphorus concentration. Biol Fertil Soils 44:501-509

Collavino MM, Sansberro PA, Mroginski LA, Aguilar OM (2010) Comparison of in vitro solubilization activity of diverse phosphate-solubilizing bacteria native to acid soil and their ability to promote Phaseolus vulgaris growth. Biol Fertil Soils 46:727-738

Cordier C, Lemoine MC, Lemanceau P, Gianinazzi-Pearson V, Gianinazzi S (2000) The benefical rhizosphere: a necessary strategy for microplant production. Acta Hortic 530:259-268 
Dick WA, Cheng L, Wang P (2000) Soil acid and alkaline phosphatase activity as $\mathrm{pH}$ adjustment indicators. Soil Biol Biochem 32:1915-1919

Dodd JC, Burton CC, Burns RG, Jeffries P (1987) Phosphatase activity associated with the roots and the rhizosphere of plants infected with vesicular-arbuscular mycorrhizal fungi. New Phytol 107:163-172

Eizavi F, Tabatabai MA (1977) Phosphatases in soils. Soil Biol Biochem 9:167-172

Ezawa T, Yoshida T (1994) Characterization of phosphatase in marigold roots infected with vesicular-arbuscular mycorrhizal fungi. Soil Sci Plant Nutr 40:255-264

Feng K, Lu HM, Sheng HJ, Wang XL, Mao J (2004) Effect of organic ligands on biological availability of inorganic phosphorus in soils. Pedosphere 14:85-92

Frankenberger WT, Bingham FT (1982) Influence of salinity on soil enzyme activities. Soil Sci Soc Am J 46:1173-1177

Gallagher JL (1985) Halophytic crops for cultivation at seawater salinity. Plant Soil 89:323-336

Garbaye J, Bowen GD (1987) Effect of different microflora on the success of ectomycorrhizal inoculation of Pinus radiata. Can $\mathrm{J}$ For Res 17:941-943

Garcia C, Hernandez T (1996) Influence of salinity on the biological and biochemical activity of a calciothid soil. Plant Soil 178:255263

Giri B, Kapoor R, Mukerji KG (2003) Influence of arbuscular mycorrhizal fungi and salinity on growth, biomass, and mineral nutrition of Acacia auriculiformis. Biol Fertil Soils 38:176-180

Giri B, Kapoor R, Mukerji KG (2007) Improved tolerance of Acacia nilotica to salt stress by arbuscular mycorrhiza, Glomus fasciculatum may be partly related to elevated $\mathrm{K} / \mathrm{Na}$ ratios in root and shoot tissues. Microb Ecol 54:753-760

Gyaneshwar P, James EK, Reddy PM, Ladha JK (2002a) Herbaspirillum colonization increases growth and nitrogen accumulation in aluminium tolerant rice varieties. New Phytol 154:131-146

Gyaneshwar P, Kumar GN, Parekh LJ, Poole PS (2002b) Role of soil microorganisms in improving $\mathrm{P}$ nutrition of plants. Plant Soil 245:83-93

Habte M, Osorio NW (2001) Arbuscular mycorrhizas: producing and applying arbuscular mycorrhizal inoculum. Collage of tropical agriculture and human resources. University of Hawaii, Manoa, pp 15-23

Hameeda B, Kumar YH, Rupela OP, Kumar GN, Reddy G (2006) Effect of carbon substrates on rock phosphate solubilization by bacteria from compost and macrofauna. Curr Microbiol 53:298302

Hoagland DR, Arnon DI (1950) The water-culture method of growing plants without soil. University of California Berkeley Coll Agric Circ 347

Jacobsen I, Abbott LK, Robson AD (1992) External hyphae of vesicular-arbuscular mycorrhizal fungi associated with Trifolium subterraneum L. New Phytol 120:371-380

Jonas FJ, Leslie RP, Roger DF (2004) Microbial interactions in the mycorrhizosphere and their significance for sustainable agriculture. FEMS Microbiol Ecol 48:1-13

Juniper S, Abbott LK (2006) Soil salinity delays germination and limits growth of hyphae from propagules of arbuscular mycorrhizal fungi. Mycorrhiza 16:371-379

Kandeler E, Tscherko D, Spiegel H (1999) Long-term monitoring of microbial biomass, $\mathrm{N}$ mineralization and enzyme activities of a chernozem under different tillage management. Biol Fertil Soils 28:343-351

Kang H, Freeman C (1999) Phosphatase and arylsulphatase activities in wetland soils: annual variation and controlling factors. Soil Biol Biochem 31:449-454
Khan MS, Zaidi A, Wani PA (2007) Role of phosphate-solubilizing microorganisms in sustainable agriculture - a review. Agron Sustain Dev 27:29-43

Kohler J, Caravaca F, Carrasco L, Roldán A (2007) Interactions between a plant growth-promoting rhizobacterium, an AM fungus and a phosphate-solubilising fungus in the rhizosphere of Lactuca sativa. Appl Soil Ecol 35:480-487

Kothari SK, Marschner H, George E (1990) Effect of VA mycorrhizal fungi and rhizosphere microorganisms on root and shoot morphology, growth and water relations in maize. New Phytol 116:303-311

Kucey RMN (1983) Phosphate solubilising bacteria and fungi in various cultivated and virgin Alberta soils. Can J Soil Sci 63:671-678

Linderman RG (1988) Mycorrhizal interaction with the rhizosphere microflora: the mycorhizosphere effect. Phytopathology 78:366371

Manjunath A, Hue NV, Habte M (1989) Response of Leucaena leucocephala to vesicular-arbuscular mycorrhizal colonization and rock phosphate fertilization in an oxisol. Plant Soil 114:127133

Mar VM, Sonia C, Rosario A, José BM (2000) Interactions between arbuscular mycorrhizal fungi and other microbial inoculants (Azospirillum, Pseudomonas, Trichoderma) and their effects on microbial population and enzyme activities in the rhizosphere of maize plants. Appl Soil Ecol 15:261-272

Mcgonigle TP, Miller MH, Evans DG, Fairchild GL, Swan JA (1990) A new method which gives an objective measure of colonization of roots by vesicular-arbuscular mycorrhizal fungi. New Phytol 115:495-501

Nannipieri P, Ceccanti B, Cervelli S, Matarese E (1980) Extraction of phosphatase, urease, proteases, organic-carbon, and nitrogen from soil. Soil Sci Soc Am J 44:1011-1016

Nannipieri P, Kandeler E, Ruggiero P (2002) Enzyme activities and microbiological and biochemical processes in soil. In: Burns RG, Dick R (eds) Enzymes in the environment. Marcel Dekker, New York, pp 1-33

Nannipieri P, Ascher J, Ceccherini MT, Landi L, Pietramellara G, Renella G (2003) Microbial diversity and soil functions. Eur J Soil Sci 54:655-670

Naseby DC, Lynch JM (1997) Rhizosphere soil enzymes as indicators of perturbation caused by a genetically modified strain of Pseudomonas fluorescens on wheat seed. Soil Biol Biochem 29:1353-1362

Nguyen C (2003) Rhizodeposition of organic C by plants: mechanisms and controls. Agronomie 23:375-396

Ogut M, Er F, Kandemir N (2010) Phosphate solubilization potentials of soil Acinetobacter strains. Biol Fertil Soils 46:707-715

Ohshima T, Tamura T, Sato M (2007) Influence of pulsed electric field on various enzyme activities. J Electrostat 65:156-161

Olsen SR, Cole CV, Watanabe FS, Dean LA (1954) Estimation of available-phosphorus in soils by extraction with sodium bicarbonate. USDA Circulation No. 939. US Government Printing Office, Washington, pp 19-27

Omar SA, Abdel-Sater MA, Khallil AM, Abd-Alla MH (1994) Growth and enzyme activities of fungi and bacteria in soil salinized with sodium chloride. Folia Microbiol 39:23-28

Osorio NW, Habte M (2001) Synergistic influence of an arbuscular mycorrhizal fungus and a $\mathrm{P}$ solubilizing fungus on growth and $\mathrm{P}$ uptake of Leucaena leucocephala in an oxisol. Arid Land Res Manag 15:263-274

Phillips JM, Hayman DS (1970) Improved procedures for clearing roots and staining parasitic and VA mycorrhizal fungi for rapid assessment of infection. Trans Br Mycol Soc 55:158-161

Piccini D, Azcon R (1987) Effect of phosphate solubilizing bacteria and vesicular-arbuscular mycorrhizal fungi on the utilization of 
Bayovar rockphosphate by alfalfa plants using a sand-vermiculite medium. Plant Soil 50:45-50

Pikovskaya RI (1948) Mobilization of phosphorus in soil in connection with the vital activity of some microbial species. Mikrobiologia 17:362

Rao S (1992) Biofertilizers in agriculture. AA Balkema, Rotterdam, p 188

Rashid M, Khalil S, Ayub N, Alam S, Latif F (2004) Organic acids production and phosphate solubilization by phosphate solubilizing microorganisms (PSM) under in vitro conditions. Pak J Biol Sci 7:187-196

Reyes I, Valery A, Valduz Z (2006) Phosphate-solubilizing microrganisms isolated from rhizospheric and bulk soils of colonizer plants at an abandoned rock phosphate mine. Plant Soil 287:69-75

Rietz DN, Haynes RJ (2003) Effects of irrigation induced salinity and sodicity on soil microbial activity. Soil Biol Biochem 35:845854

Riley D, Barber SA (1969) Bicarbonate accumulation and pH changes at the soybean root-soil interface. Soil Sci Soc Am Proc 33:905908

Riley D, Barber SA (1970) Salt accumulation at the soybean root-soil interface. Soil Sci Soc Am Proc 34:154-155

Rodriguez H, Fraga R (1999) Phosphate solubilizing bacteria and their role in plant growth promotion. Biotechnol Adv 17:319-339

Rozema J, Arp W, van Diggelen J, van Esbroek M, Broekman R, Punte H (1986) Occurrence and ecological significance of vesicular-arbuscular mycorrhiza in the salt marsh environment. Acta Bot Neerl 35:457-467

Ruan CJ, Qin P, Xi YG (2005) Floral traits and pollination modes in Kosteletzkya virginica (Malvaceae). Belg J Bot 137:49-55

Ruan CJ, Mopper S, Teixeira da Silva JA, Qin P, Zhang QX, Shan Y (2009a) Context-dependent style curvature in Kosteletzkya virginica (Malvaceae) offers reproductive assurance under unpredictable pollinator environments. Plant Systemat Evol 277:207-215

Ruan CJ, Zheng X, Jaime A, da Teixeira S, Qin P (2009b) Callus induction and plant regeneration from embryonic axes of Kosteletzkya virginica. Sci Hortic 120:150-155
Ruiz-Lozano JM, Azcón R (2000) Symbiotic efficiency and infectivity of an autochthonous arbuscular mycorrhizal Glomus sp. from saline soils and Glomus deserticola under salinity. Mycorrhiza 10:137-143

Ruiz-Lozano JM, Azcón R, Gómez M (1996) Alleviation of salt stress by arbuscular-mycorrhizal Glomus species in Lactuca sativa plants. Physiol Plant 98:767-772

Matiasa SR, Paganoa MC, Muzzi FC (2009) Effect of rhizobia, mycorrhizal fungi and phosphate-solubilizing microorganisms in the rhizosphere of native plants used to recover an iron ore area in Brazil. Eur J Soil Biol 45(3):259-266

Sannazzaro AI, Ruíz OA, Alberto EO, Menendez AB (2006) Alleviation of salt stress in Lotus glaber by Glomus intraradices. Plant Soil 285:279-287

Singh S, Kapoor KK (1999) Inoculation with phosphate-solubilizing microorganisms and a vesicular-arbuscular mycorrhizal fungus improves dry matter yield and nutrient uptake by wheat grown in a sandy soil. Biol Fertil Soils 28:139-144

Tarafdar JC, Marschner H (1995) Dual inoculation with Aspergillus fumigates and Glomus mosseae enhances biomass production and nutrient-uptake in wheat (Triticum aestivum L.) supplied with organic phosphorus as Na phytate. Plant Soil 173:97-102

Toro M, Azcon R, Herrera R (1996) Effects on yield and nutrition of mycorrhizal and nodulated Pueraria phaseolides exerted by Psolubilizing rhizobacteria. Biol Fertil Soils 21:23-29

Trasar-Cepeda C, Camin F, Leiro MC, Gil-Sotres F (1999) An improved method to measure catalase activity in soils. Soil Biol Biochem 31:483-485

Tripathi S, Kumari S, Chakraborty A, Gupta A, Chakrabarti K, Bandyapadhyay BK (2006) Microbial biomass and its activities in salt-affected coastal soils. Biol Fertil Soils 42:273-277

Wang FY, Liu RJ (2001) A preliminary survey of arbuscular mycorrhizal fungi in saline alkaline soil of the Yellow river delta. Biodivers Sci 9:389-392

Whitelaw MA, Harden TJ, Bender GL (1997) Plant growth promotion of wheat inoculated with Penicillium radicum sp. nov. Aust J Soil Res 35:291-300 